\title{
BMJ Open 'Connecting the dots' for generating a momentum for Universal Health Coverage in Bangladesh: findings from a cross-sectional descriptive study
}

\author{
Syed Masud Ahmed, ${ }^{1}$ Lal B Rawal, ${ }^{2,3}$ Nahitun Naher, ${ }^{1}$ Tarek Hossain ${ }^{1}$
}

To cite: Ahmed SM, Rawal LB, Naher $\mathrm{N}$, et al. 'Connecting the dots' for generating a momentum for Universal Health Coverage in Bangladesh: findings from a cross-sectional descriptive study. BMJ Open 2019;9:e024509. doi:10.1136/ bmjopen-2018-024509

- Prepublication history and additional material for this paper are available online. To view these files, please visit the journal online (http://dx.doi. org/10.1136/bmjopen-2018024509).

Received 4 June 2018 Revised 18 June 2019 Accepted 24 June 2019

Check for updates

(C) Author(s) (or their employer(s)) 2019. Re-use permitted under CC BY-NC. No commercial re-use. See rights and permissions. Published by BMJ.

${ }^{1}$ Centre of Excellence for Health Systems and UHC, James $P$ Grant School of Public Health, BRAC University, Dhaka,

Bangladesh

${ }^{2}$ School of Social Science and Psychology, Western Sydney University, Penrith, New South Wales, Australia

${ }^{3}$ Health Systems and Population Studies Division, ICDDR,B, Dhaka, Bangladesh

Correspondence to Dr. Syed Masud Ahmed; ahmed.sm@bracu.ac.bd

\section{ABSTRACT}

Objective This study was conducted to explore how and whether, the strategic grants made by the Rockefeller Foundation (RF) in different sectors of health systems in the inception phase were able to 'connect the dots' for 'generating a momentum for Universal Health Coverage (UHC)' in the country.

Design Cross-sectional descriptive study, using document review and qualitative methods.

Setting Bangladesh, 17 UHC-related projects funded by the RF Transforming Health Systems (THS) initiative during 2010-2013.

Data Available reports of the completed and on-going UHC projects, policy documents of the government relevant to UHC, key-informant interviews and feedback from grant recipients and relevant stakeholders in the policy and practice.

Outcome measures Key policy initiatives undertaken for implementing UHC activities by the government post grants disbursement.

Results The RF THS grants simultaneously targeted and connected the academia, the public and non-profit development sectors and news media for awarenessbuilding and advocacy on UHC, develop relevant policies and capacity for implementation including evidence generation. This strategy helped relevant stakeholders to come together to discuss and debate the core concepts, scopes and modalities of UHC in an attempt to reach a consensus. Additionally, experiences gained from implementation of the pilot projects helped in identifying possible entry points for initiating UHC activities in a low resource setting like Bangladesh.

Conclusions During early years of UHC-related activities in Bangladesh, strategic investments of the RF THS initiative played a catalytic role in sensitising and mobilising different constituencies for concerted activities and undertaking necessary first steps. Learnings from this strategy may be of help to countries under similar conditions of 'low resource, apparent commitment, but poor governance,' on their journey towards UHC.

\section{INTRODUCTION}

Experiences from health reforms towards Universal Health Coverage (UHC), especially in high-income countries (eg, Germany, England and later the 'Asian Tigers'), show

\section{Strengths and limitations of this study}

- In this study, we reviewed and reflected on Rockefeller Foundation (RF)'s multi-pronged investment strategy in Bangladesh to 'generate a momentum for Universal Health Coverage (UHC)' around 2011-'necessary for initiating relevant activities'.

- We reviewed 17 RF Transforming Health System project reports (completed and nearly completed) funded during 2010-2013, available at the time of the study.

- Outcomes of these projects were directly relevant to subsequent policy and practices undertaken towards initiating the UHC process in the country. Thus, the study covered sufficient grounds for making sound conclusion about the 'catalytic' role of these grants.

- Being an ex-post assessment, more in-depth analysis could not be made, except establishing a temporal association of the policies developed following the grants made in specific areas.

that politics and political structures are at the core of all such reforms. ${ }^{1-3}$ The other important factors for accelerating progress towards UHC include availability of economic resources, extent of population heterogeneity and last but not the least, window(s) of a 'historical' opportunity. ${ }^{3}$ The strong relationship between 'political settlement' ('the balance of power between contending social groups and social classes') and progress towards UHC is further explored recently. ${ }^{4}$ In this review, the authors have proposed specific strategies to advance UHC in case of specific types of political settlements, thus throwing a challenge before its advocates/ activists to find the 'best-fit' strategy for this purpose in context.

Kelsall et al proposed three types of strategies for three specific types of political settlements to advance the cause of UHC in low-income and middle-income countries (LMICs): (1) providing technical support and funding in case of a state-led 
pathway with strong commitment for UHC (strategy: 'government-supporting'); (2) substituting much of the state provision and fund in case of a highly dysfunctional state with poor commitment for UHC (strategy: 'government-substituting') and finally, (3) connecting elements in the state and polity with market and civil society in case of a state with apparent commitment and some funding capability for UHC, but weak implementation due to poor governance and interest group politics (strategy 'government-connecting'). According to this analysis, Bangladesh is classified within the last category, that is, a state with apparent commitment (and some funding for UHC) but with questionable implementation capacity due to weak governance from 'clientilist' politics. ${ }^{56}$ Despite the existence of a health system frequently characterised as 'weak, fragmented and poorly resourced,-, Bangladesh has managed to expand service delivery, reduce disease burdens and improve overall population health outcomes in recent times, ${ }^{8}$ at a 'low cost' compared with its neighbours of comparable socioeconomic conditions. ${ }^{9}{ }^{10}$ The success factors underlying these achievements have been described elsewhere. ${ }^{11}$ To consolidate these achievements further, the government of Bangladesh made commitment to achieve UHC for all its citizens at the 64th World Health Assembly (WHA) in May 2011. ${ }^{12}$ During this time, UHC was a relatively novel concept among the policymakers and practitioners and it moved high up the health agenda only following the endorsement of sustainable development goals (Goal 3, Target 3.8) by the United Nations General Assembly in 2015. Early on, to fulfil the political commitment made in the WHA, a Healthcare Financing Strategy (HCFS) 2012-2032 was formulated and subsequently, also a UHC Communication strategy 2014 -2016. Since then, Bangladesh has taken some key initiatives (eg, Health Workforce Strategy 2015, Quality Improvement Strategy 2015, Social Security Strategy 2015) to facilitate UHC agenda where support from the Rockefeller Foundation (RF) played a critical role since its grants investment began in January 2009. ${ }^{13}$

The grants-making 'Transforming Health System (THS)' initiative of the RF sought to advance the UHC agenda in four LMICs, for example, Bangladesh, Ghana, Rwanda and Vietnam, which were characterised by varying levels of political commitment and resources for UHC. The ultimate aim was to strengthen the health systems of these countries by facilitating relevant reforms to address the challenges of implementing UHC in an environment of pluralistic health system. Thus, a multipronged strategy was designed to connect the 'dots', that is, elements important for catalysing UHC agenda in the public and non-state sectors for having a consolidated larger outcome and impact. ${ }^{13}$

The four 'focus areas' where these grants were made included (1) policy and advocacy (for improving UHC awareness and commitment, and subsequent policy development); (2) health systems stewardship and management (for building capacity of healthcare professionals to lead UHC reforms); (3) health information systems (for using Information and Communication Technology for developing infrastructure for e-Health) and (4) health financing mechanisms (for exploring different pre-payment and risk-pooling options). Besides public sector institutions, grants were also provided to a broad range of civil society/non-government organisations and independent research institutions for developing a 'critical mass' of advocates for UHC. Its grants enabled piloting various health insurance/pre-payment modules that could eventually serve as a prototype for a national health insurance system.

Further, a Centre of Excellence for UHC (http://www. coe-uhc.org) was established in 2011 at the BRAC JPG School of Public Health, BRAC University for advocacy, capacity building and evidence generation for facilitating UHC activities in the country. Finally, the Centre conducted this study to explore whether and how the above strategic investments of RF helped in generating a 'momentum for UHC' in Bangladesh, and summarise the learning and challenges to inform future UHC initiation activities in countries undergoing similar socioeconomic and health conditions.

\section{MATERIALS AND METHODS}

This cross-sectional descriptive study is based on a review of reports from a number of completed and near-completed RF THS Grant projects, and relevant policy documents of the government. This was supplemented by key informant interviews (KII) with relevant stakeholders at the policy and practice levels, including feedback received from a round-table dialogue organised at the conclusion of the study.

\section{Review of documents}

In all, we reviewed 11 national policy and strategy documents of the GoB, and 17 RF THS grant projects (out of total 27 funded during 2010-2013) with an available end-of-project or mid-term project report and having direct relevance to initiate UHC activities in the country. Examples of excluded ones not directly related to UHC initiatives include grants for producing a Lancet series on innovation for UHC in Bangladesh, establishing a health system disease surveillance in a national institute of epidemiology and surveillance and a Centre of Excellence for UHC (Bangladesh); support a satellite session on discussing the progress of UHC in Bangladesh at the Prince Mahidol Award Conference (PMAC) in Bangkok, Thailand and establish an eHealth association in Pakistan (for a full list, please see online supplementary table A).

\section{Key informant interviews}

The key informants $(n=21)$ included principal investigators of the above projects, relevant policy elites from the Ministry of Health and Family Welfare (MoHFW) of the $\mathrm{GoB}$, and development partners, researchers and academicians involved in facilitating/implementing UHC-relevant activities. A guideline developed for this purpose 
explored mainly two themes: (1) current UHC scenario in the country including understanding of the concepts, scopes and components of UHC, identifying priority areas for action including challenges and opportunities and dynamics of RF involvement and (2) specific experiences gained and lessons learnt in the process of implementing the different grant projects (online supplementary table B).

\section{Round-table dialogue}

A discussion meeting in the form of a round-table dialogue was organised with the stakeholders as a concluding event of the study. The participants of this meeting were those who took part in the KIIs, representatives of the development partners, policy elites from the MoHFW and representatives of non-profit organisations working in the health sector.

\section{Data synthesis and analysis}

Given the data being mostly qualitative, we used framework method of analysis following Gale et al. ${ }^{14}$ The framework method is appropriate for comparing and contrasting large-scale textual data (in this case, information from the KIIs) and synthesising the data in a thematic way ('a holistic, descriptive overview'), especially when there is a multidisciplinary research team involved. This approach identifies commonalities and differences in qualitative data before focusing on relationships between different parts of the data, thereby seeking to draw descriptive and/ or explanatory conclusions clustered around themes, and now used widely in health research. ${ }^{14-17}$

All interviews and notes taken in Bangla were translated into English. A sample of transcripts was read and re-read by the study team members (NN, TH, LBR and SMA) independently to develop an initial coding matrix of themes and categories. This was discussed, refined and agreed before the remainder of the transcripts were prepared and analysed using the agreed coding framework. All translated transcripts were compiled, and read multiple times in order to facilitate data familiarisation. Then, the data were coded, an analysis framework was developed in a tabular form with themes and sub-themes and the analytic matrix was populated with compiled data (online supplementary table C).

\section{Role of the researchers}

The study was conducted by a group of researchers affiliated with the CoE-UHC under BRAC JPGSPH, BRAC University. These researchers were not involved in the design or implementation of any of the grant projects included in the study neither they were beneficiaries of these projects. Their role was specifically restricted to the assessment of these grants vis-à-vis RF THS grants as described above. They were involved in research and advocacy activities totally unrelated to the above projects, which ensured their objectiveness in conducting this study and minimise any individual bias.

\section{Patient and public involvement}

This study was based on review of published and unpublished literature, reflections from key-informant interviews and a round-table discussion. The respondents in the latter two were either recipients of the RF THS initiative grants or were stakeholders in the UHC process (eg, academia, development partners and non-profit sector representatives). Patients or the public were not directly involved or participated in the research.

\section{Ethical considerations}

The ethical clearance of this study was obtained from the ethics review committee of the BRAC JPG School of Public Health, BRAC University. Before the interviews, the key informants were apprised about the study and their written consents obtained including consent for tape recording the interviews. Privacy and confidentiality of interviews and information collected were maintained at all stages. Data were used for research purpose only.

\section{RESULTS}

Findings reveal how the grants in the four THS focus areas displayed temporal association with subsequent development of policy and practices related to UHC implementation in Bangladesh (figure 1). These are described below according to the activities delineated in the Methods section.

\section{Review of the RF THS funded UHC project reports}

Review of the 17 project reports reveals that the RF grants were distributed mainly in the four THS focus areas described above which had a direct bearing on advancing the UHC agenda in the country (table 1). Activities undertaken under these four focus areas and subsequent policy and strategy development from these actions are summarised to show how the different 'dots' were connected (table 2). These are discussed thematically below.

\section{Policy and advocacy for UHC}

This activity included organising experience-gathering tours to countries that have displayed reasonable progress on the journey towards UHC. These first-hand experiences in similar socioeconomic conditions convinced the policymakers about the benefits and feasibility of implementing UHC also in Bangladesh. This awareness to policy development process was reflected in formulating a number of strategies and plans essential for launching the UHC agenda such as an HCFS for below poverty line population and the informal sector, and a plan for production of adequate and balanced health workforce in order to achieve UHC by 2030. A project on service quality focused on developing hospital accreditation system in Bangladesh.

\section{Capacity development for UHC}

The funded projects on capacity development ranged from developing and offering post-graduate courses in 


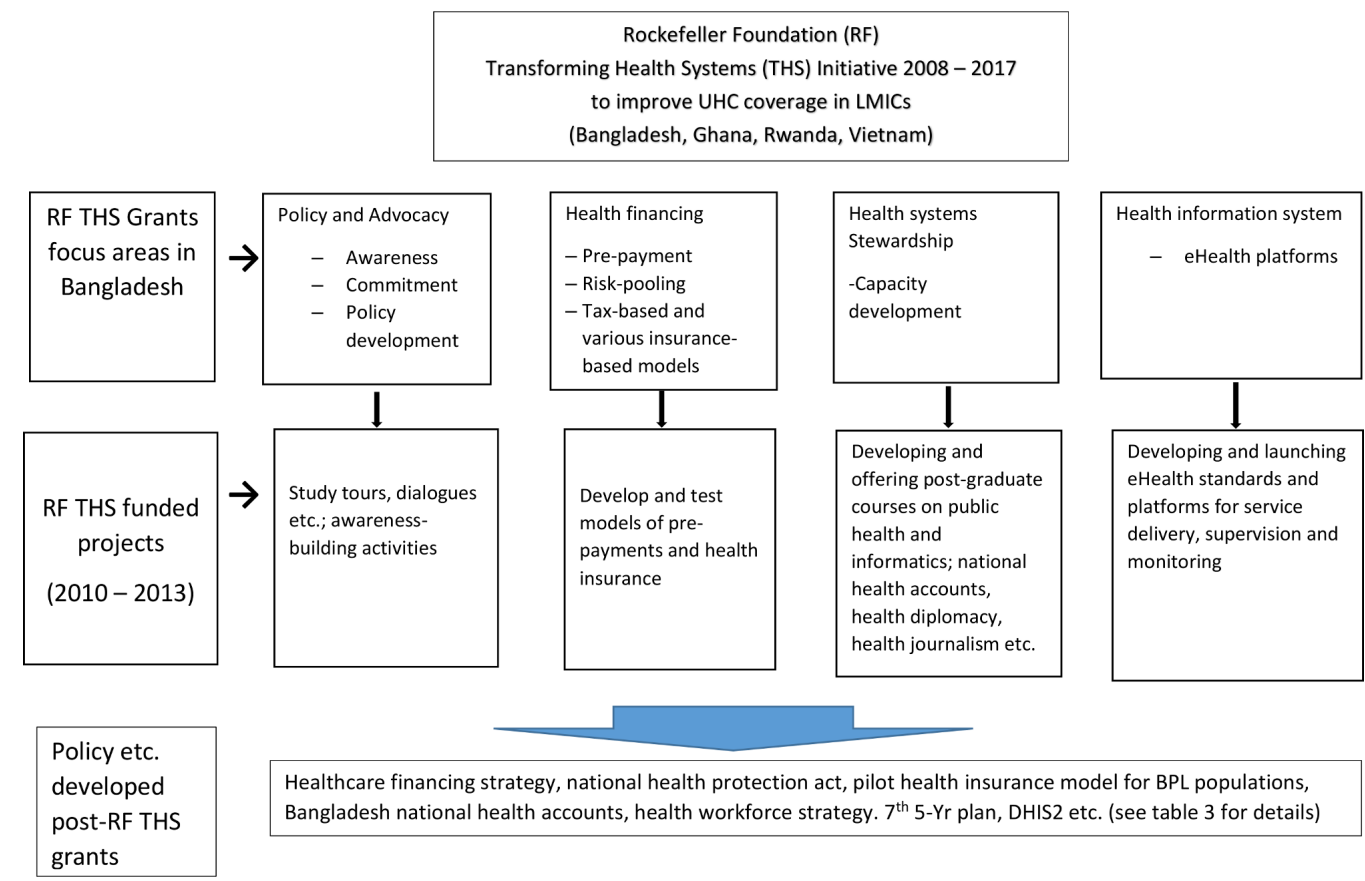

Figure 1 Conceptual framework linking RF THS grants in its targeted focus areas (2010-2013) and subsequent developments in policy and practice to facilitate UHC agenda in Bangladesh. BPL, below poverty line; DHIS2, district health information system 2; LMICs, low-income and middle-income countries; RF THS, Rockefeller Foundation's Transforming Health System; UHC, Universal Health Coverage.

public health and/or informatics in private and public sector universities to training of the members of the Bangladesh National Health Accounts team on analytical skills, and training doctors on developing awareness on and promotion of ethical practices in delivering healthcare services. THS grants were also used to develop critical skills in areas such as health diplomacy for bureaucrats, and reporting health and UHC issues for health journalists.

\section{Exploring models of pre-payments/health insurance for UHC}

The different pre-payment (a fixed amount paid in advance by the households, in single or multiple instalments annually, for coverage of defined health services) and health insurance pilots (micro health insurance/ social health insurance) were implemented mainly to offer essential healthcare services with financial protection, with community health insurance schemes especially focusing the poor. Findings reveal that the concept of current risk pooling for future healthcare cost through pre-payment was relatively novel among the community and the concept of paying at present for a future event was not culturally acceptable to majority of the population of Bangladesh due to their fatalistic religious beliefs and norms. Besides, voluntary nature of enrolment into the schemes hampered optimum risk and resource pooling, threatening sustainability of the schemes. There were problems with renewal of policies by poor households because of lack of one-stop services (all essential services under one roof), healthcare access problems and quality of services provided. The absence of comprehensive sociodemographic database was another hurdle that these projects faced. However, the projects made some progress in sensitising the community with the concept of pre-payment and its effect on reducing out-of-pocket expenditure for illness episodes.

\section{eHealth platform for accelerating UHC}

Projects on using ICT for 'leap frogging' ('the notion that areas which have poorly-developed technology ...can move themselves forward rapidly through the adoption of modern systems without going through intermediary steps') ${ }^{18}$ of UHC activities were directed for strengthening the existing health information systems through the development of a national e-health oversight body and e-health standards and interoperable platform for shared health records. This upgraded district health information system facilitated the collection of data on 100 Core Health Indicators and is used for aggregate analysis by MoHFW for policy decisions including the production of its flagship publication Health Bulletin ${ }^{19}$, and also, local health bulletins.

\section{Review of Government of Bangladesh policy/strategy documents after 2011 with implications for UHC}

Altogether, 11 policy documents produced by the GoB between 2012 and 2015 were reviewed focusing on its objectives/strategies adopted and proposed action plans/implementation activities (table 3). RF THS investments played a crucial role in initiating these activities in policy and practice, either through direct investment or indirectly through capacity building and supporting the key stakeholders in different constituencies. For example, Bangladesh, with its spending of only around 3\% of the 


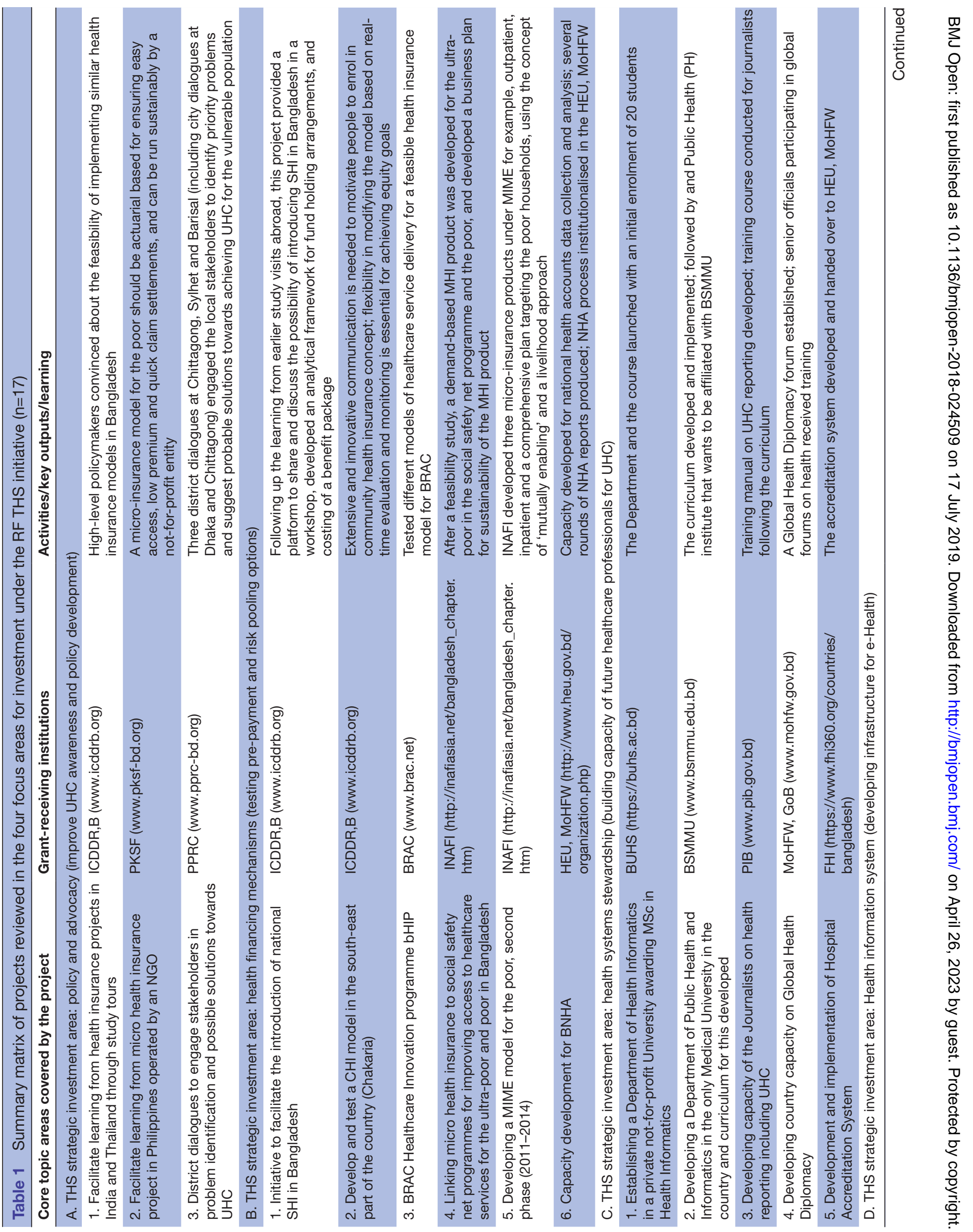


gross domestic product $(<1 \%$ by the public sector) on health and high out-of-pocket expenditure for healthcare (around two-thirds of the total health expenditure), was in desperate need of an HCFS to achieve UHC by 2030s. This was addressed by the MoHFW's HCFS 2012-2032, which laid out a plan for generating more resources and enhancing efficiency in resource utilisation for equitable service delivery and cover the entire population gradually by 2032 .

A pilot social health protection scheme (Shasthyo Surokhasha Karmasuchi) is developed by the Health Economics Unit of the MoHFW and launched in the same year to test feasibility of the above financing strategy for population living below poverty line. Further, to provide a legal framework to support the HCFS, the GoB drafted a 'National Health Protection Act, 2014' which identified national health protection authorities, accreditation committees, source and mechanism of fund transfers and service packages with delineation of providers and beneficiaries. The country also produced successive reports on National Health Accounts supported by RF funds, to inform policymakers and other stakeholders of the magnitude and profile of health spending and resource flows. Besides the above initiatives for facilitating UHC, other activities included Bangladesh Health Workforce strategy for estimation and production of required health workforce, a National Strategic Planning of Quality of Care for Health Service Delivery, for ensuring quality of services provided, and also, launching publichealth departments and offering post-graduate courses in public health and/ or health informatics as part of its capacity development efforts.

\section{Feedback from the key informants}

This section summarises the feedback received from KIIs with selected RF THS grantees, development partners and other stakeholders working for advancing UHC agenda in Bangladesh. These are described below thematically, according to the four THS focus areas.

\section{UHC awareness}

Most of the RF grantees and others expressed that the concept of UHC was not entirely new, that its precursor primary healthcare (PHC) has been around long since 1978 Alma Ata declaration of HFA by 2000. Since then, government has taken quite a number of measures to improve the PHC infrastructure in the country, along with improvements in other sectors including education, road transport, electricity, communication, etc. All of these together contributed in achieving better population health outcomes, particularly health-related millennium development goals. To quote an informant,

Lots of policymakers see UHC as nothing new... what is happening right now is the 'improvement' of previous works they have already been doing. (A development partner) 
Table 2 Linking RF THS grants in four focus areas to subsequent policy and practice for implementing UHC-related activities

THS focus areas for strategic investments

I. Policy and advocacy
(improve UHC awareness
and commitment for
subsequent policy
development)

II. Health financing mechanisms (testing prepayment options by risk pooling)

III. Health systems
stewardship (building
capacity of healthcare
professionals and health
journalists for facilitating
UHC agenda)

IV. HIS (developing

infrastructure for e-Health)
Activities undertaken by RF THS grant projects to facilitate UHC agenda

THS grants for experience gathering tours abroad in countries with successful track record in achieving UHC through various pre-payment and risk-pooling mechanisms organised; High-level policymakers became convinced about the benefits and feasibility of implementing UHC in Bangladesh

THS grants for capacity development of the government (HEU, MoHFW in doing national health accounts and establishment of a BNHA cell in the HEU; multiple grants in exploring various models of social and communitybased health micro-insurance explored and tested for finding out the optimum one for Bangladesh

THS grants for UHC skills-building courses for health professionals including Master level courses in public health and informatics; capacity development in analysing and preparing reports on National Health Accounts; THS grants to develop critical skills in areas such as health diplomacy for bureaucrats and writing on issues related to UHC for the journalists

Review of current HIS to identify gaps towards

development of a standardised, interoperable, common platform for data gathering, consolidating and sharing through the use of ICT and improve performance
'Connecting the dots': relevant policies/strategies/ activities in government and non-state sectors following RF THS grants

Political commitment for UHC expressed from highest level of government and endorsed in subsequent policy and strategy docs; some initial steps taken such as formulating strategies for awareness-building and communication, improving QoC and health workforce production.

A Healthcare Financing strategy formulated for achieving UHC by 2030 in successive steps; a health insurance model (Sasthya Surokha Kormusuchi, Health Security Programme) is being piloted for the BPL population informed by findings from the RF THSfunded social/community-based experiments

Departments of Public Health and Health Informatics established in public and private universities to produce capable leaders for advancing UHC in future; THS grants used for attending global health meetings to have hands-on training and experiences on health diplomacy; skill-building workshops held by PIB for journalists

THS grants in this area were crucial in initiating relevant e-Health activities

BNHA, Bangladesh National Health Account; BPL, below poverty line; HEU, Health Economics Unit; HIS, health information system; ICT, information and communications technology; MoHFW, Ministry of Health and Family Welfare; PIB, Press Institute Bangladesh; QoC, quality of care; RF THS, Rockefeller Foundation's Transforming Health System; UHC, Universal Health Coverage.

However, some informants expressed scepticism about the differences in understanding about the UHC process, especially at the national and sub-national levels. One informant mentioned,

The concept of UHC is not clear in Bangladesh, I think even at policy level the perception is not clear, so at bottom level it will take time. (An RF grantee)

The respondents emphasised the need for redefining UHC in the context of Bangladesh and develop a feasible strategy:

... I think now we are in a phase to redefine UHC in our country context and develop country strategies for UHC accordingly. (An RF grantee)

\section{Pre-payment and micro-insurance experiences}

Pilot-testing pre-payment options such as micro health insurance models was identified as a major challenge due to existing knowledge gap on UHC. As one grantee mentioned,

The concept of insurance is a struggling one... the people of Bangladeshi are largely fatalistic and perceive the future bestowed in the hand of the almighty and no one can control future... so the concept of insurance controlling future is difficult for them to accept. (An RF grantee)
Again, according to the law of the land for implementing an insurance scheme, the organisation need to be registered as an insurance company and this regulatory provision has been a concern for the grantees who were involved in testing micro health insurance programme. One grantee shared his experience as

...if we need to implement our insurance programme then we need to be registered as an insurance company. (An RF grantee)

Besides, difficulties in identifying partners, peer competition, limited capacity, lack of coordination among partners and so on were highlighted as some of the key challenges of working in this field. Lack of motivation among professionals and high dropout rate of field-level stuffs were pointed as implementation-level challenge. As one grantee reflected,

We faced challenges in motivating professionals for piloting the hospital accreditation project... the doctors were asked to fill up the form but they were not interested to do it..... (An RF grantee)

However, according to them, these projects enabled them to understand the field-level challenges and barriers associated with the operation of these insurance projects. This helped in re-designing the projects such as a wider choice of providers to increase enrolment and satisfaction of the clients, real-time monitoring of the scheme, 
Table 3 Review of policy/strategy/legal docs of the government relevant to the UHC agenda following award of the RF THS grants

\begin{tabular}{|c|c|c|c|}
\hline $\mathbf{S} / \mathbf{N}$ & $\begin{array}{l}\text { Key policy/strategy/legal } \\
\text { documents relevant to UHC } \\
\text { agenda following award of } \\
\text { RF THS grants }\end{array}$ & Stated objective(s)/strategy(ies) & Implementation activities/plans \\
\hline 1 & $\begin{array}{l}\text { Healthcare Financing Strategy } \\
\text { 2012-2032 } \\
\text { (HEU/MoHFW }\end{array}$ & $\begin{array}{l}\text { Formulated with three main } \\
\text { objectives: (1) generate more } \\
\text { resources, (2) improve equity in } \\
\text { service delivery and (3) enhance } \\
\text { efficiency in resource utilisation. }\end{array}$ & $\begin{array}{l}\text { To be implemented in three time bound } \\
\text { periods - short term, medium term and long } \\
\text { term to cover the entire population gradually } \\
\text { by } 2032 \text {. } \\
\text { - Tax-funded publicly financed healthcare, } \\
\text { safety net scheme, community-based health } \\
\text { insurance and so on, planned to reach this } \\
\text { goal. }\end{array}$ \\
\hline 2 & $\begin{array}{l}\text { National Health Protection Act } \\
2014 \\
\text { (MoHFW) }\end{array}$ & $\begin{array}{l}\text { To provide a legal framework to } \\
\text { support HCFS 2012-2032 }\end{array}$ & $\begin{array}{l}\text { The draft act identified national health } \\
\text { protection authorities, accreditation } \\
\text { committee, source and mechanism of fund, } \\
\text { services, providers and beneficiaries to be } \\
\text { finalised for enabling the implementation of } \\
\text { HCFS 2012-2032 }\end{array}$ \\
\hline 3 & $\begin{array}{l}\text { SSK pilot } 2015 \\
\text { (HEU/MoHFW) }\end{array}$ & $\begin{array}{l}\text { A social health protection } \\
\text { scheme developed to enrol BPL } \\
\text { beneficiaries in providing outpatient } \\
\text { and inpatient services from selected } \\
\text { public sector health facilities }\end{array}$ & $\begin{array}{l}\text { Covered randomly selected nine unions and } \\
\text { two paurashavas of three pilot upazilas using } \\
\text { probability sampling approach }\end{array}$ \\
\hline 4 & $\begin{array}{l}\text { Bangladesh National Health } \\
\text { Accounts 1997-2015 } \\
\text { (HEU/MoHFW) }\end{array}$ & $\begin{array}{l}\text { The main objective is to inform } \\
\text { national policymakers and other } \\
\text { stakeholders of the magnitude and } \\
\text { profile of health spending, bedsides } \\
\text { capacity development for analysing } \\
\text { health accounts using standard } \\
\text { methodology. } \\
\text { To develop capacity to analyse } \\
\text { health accounts and produce report } \\
\text { at regular intervals, since need of } \\
\text { significant steps that have to be } \\
\text { taken for reducing households OOP } \\
\text { health-related expenditures and } \\
\text { also to address regional disparities } \\
\text { in health expenditure }\end{array}$ & $\begin{array}{l}\text { NHA tracks the total health expenditure in } \\
\text { Bangladesh between the fiscal years } 1997 \\
\text { and } 2012 \text {, cross-stratified and categorised } \\
\text { by source of financing and classification of } \\
\text { providers, and function on an annual basis; } \\
\text { the current one is the fifth one in a row. }\end{array}$ \\
\hline 5 & $\begin{array}{l}\text { National Strategic Planning } \\
\text { of Quality of Care for Health } \\
\text { Service Delivery } 2015 \\
\text { (General Economics Division/ } \\
\text { Planning Commission, GoB) }\end{array}$ & $\begin{array}{l}\text { To define, measure and improve the } \\
\text { quality of services delivered through } \\
\text { a comprehensive approach }\end{array}$ & $\begin{array}{l}\text { An implementation plan and } \\
\text { required organisational structure has been } \\
\text { outlined to address the core objectives }\end{array}$ \\
\hline $6 / 7$ & $\begin{array}{l}\text { Bangladesh Health Workforce } \\
\text { strategy 2016-2020; } \\
\text { Workforce Strategy 2013-2023 } \\
\text { (Human Resource } \\
\text { Management Unit/MoHFW) }\end{array}$ & $\begin{array}{l}\text { To make available appropriately } \\
\text { trained, motivated, adequate } \\
\text { number of workforce for attainment } \\
\text { of health-related SDGs and UHC. } \\
\text { The actions needed outlined as the } \\
\text { short-term (2016-2017), medium- } \\
\text { term (2018-2021) and long-term } \\
\text { (2022-2030) actions }\end{array}$ & $\begin{array}{l}\text { Capacity development activities to } \\
\text { improve skills-mix, quality assurance, task } \\
\text { shifting, accreditation, training; developed } \\
\text { a Workforce Plan aligned with projected } \\
\text { need to close the existing gaps; to promote } \\
\text { evidence-based decision making, develop } \\
\text { central HWF information system; promote } \\
\text { and maintain high standards in performance }\end{array}$ \\
\hline
\end{tabular}




\begin{tabular}{|c|c|c|c|}
\hline $\mathbf{S} / \mathbf{N}$ & $\begin{array}{l}\text { Key policy/strategy/legal } \\
\text { documents relevant to UHC } \\
\text { agenda following award of } \\
\text { RF THS grants }\end{array}$ & Stated objective(s)/strategy(ies) & Implementation activities/plans \\
\hline 8 & $\begin{array}{l}\text { Seventh Five Year Plan 2016- } \\
2020 \\
\text { (General Economics Division/ } \\
\text { Planning Commission, GoB) }\end{array}$ & $\begin{array}{l}\text { To deliver quality health services for } \\
\text { all; to achieve adequate and stable } \\
\text { supply of safe and nutritious food } \\
\text { for everyone, especially women } \\
\text { and children; to reduce the fertility } \\
\text { rate; to strengthen capacities of the } \\
\text { Community Clinics, Upazila health } \\
\text { complexes and district hospitals }\end{array}$ & $\begin{array}{l}\text { Plans to improve health outcome indicators } \\
\text { from current levels }\end{array}$ \\
\hline $9 / 10$ & $\begin{array}{l}\text { Launching post-graduation } \\
\text { departments on public health/ } \\
\text { informatics in Universities }\end{array}$ & $\begin{array}{l}\text { Courses on MPH and Informatics } \\
\text { (BSMMU), and Master of } \\
\text { Informatics (BUHS) started, } \\
\text { respectively, in public and private } \\
\text { universities }\end{array}$ & $\begin{array}{l}\text { Course curriculum developed, faculty } \\
\text { recruited and trained and courses offered }\end{array}$ \\
\hline 11 & $\begin{array}{l}\text { Development and use of } \\
\text { e-platforms }\end{array}$ & $\begin{array}{l}\text { Launching e-platforms for provision } \\
\text { and monitoring of healthcare } \\
\text { service delivery }\end{array}$ & DHIS2 developed and launched \\
\hline
\end{tabular}

BPL, below poverty line; DHIS2, District Health Information System 2; GoB, Government of Bangladesh; HCFS, Health Care Financing Strategy; HEU, Health Economics Unit; MoHFW, Ministry of Health and Family Welfare; MPH, Master of Public Health; OOP, out-of-pocket; RF THS, Rockefeller Foundation Transforming Health System; SDGs, sustainable development goals; SSK, Shasthyo Surokhasha Karmasuchi; UHC, Universal Health Coverage.

enabling regulatory framework and making the insurance mandatory for a community instead of operating it as a voluntary scheme. They were convinced about the necessity of comprehensive awareness-building on the pros and cons of the scheme so that there is no misunderstanding and overexpectation is minimised. For this, the grantees mentioned about aspects of UHC beyond insurance and advocated for cross-sectoral open platform to continue the discussion on UHC efforts. The grantees emphasised the fact that when there is trust in the institution implementing it, people of different income groups were willing to make pre-payments for healthcare.

Health systems stewardship by the government

Most of the KI respondents agreed that the government should take stewardship role for implementing UHC in Bangladesh. One of them observed,

It seems that there are a lot of interests on UHC but if the leadership or ownership doesn't come from the government, it will be a challenge for everyone to do something for UHC. (An RF grantee)

and also,

... it is for the government to strengthen its stewardship role in making necessary changes towards UHC in the country. (An RF grantee)

But most of the informants were doubtful about the capacity of the government to take this role, and also, about the willingness to accommodate other stakeholders such as the private/NGO sectors in the process:
The government alone can't achieve UHC. (An RF grantee)

The government knows that the private sector has a role to contribute, but not acknowledging it properly. (An RF grantee)

They were also concerned about lack of coordination among various ministries of the government and agencies, over and above that with the non-state sectors, deemed essential for concerted actions to drive UHC agenda:

It is not only challenging to coordinate with the nonstate actors, but coordination within the government is also a problem. (An RF grantee)

How RF THS grants helped: perspectives of the stakeholders The respondents were unanimous about the key role played by the investments through RF's THS programme in developing interest and discussion around UHC:

RF involvement was extremely helpful to set the stage when nobody has thought about UHC in Bangladesh... RF may not be the catalyst but one of the main contributors to bring the UHC in Bangladesh...for that I would say thanks to RF. (An $\mathrm{RF}$ grantee)

Another informant observed that RF investment was helpful for evidence generation and capacity development, for example, through the establishment of the Centre for UHC at JPGSPH, BRAC University, which 
helped create a positive environment for UHC movement in the country:

A modest favourable environment has been created... it is difficult to directly attribute to RF investment but many of it goes in favour of RF...nothing would have happened without RF contribution. (An RF grantee)

However, some participants were critical of the fact that though RF multi-pronged investments initiated quite a number of works (many stones were thrown and many windows have opened) but the orchestration in terms of scaling up was missing:

The momentum has been created but I would say this momentum is more like ingredients of a good quality curry but the curry has not been cooked yet. (An RF grantee)

A few development partners complained about not being included in the process:

There was no structured discussion among development partners and RF before they started giving funds for UHC. (A development partner)

And some also critically reflected on capacity development through new departments, for example,

We need to make already existing things more active than investing in new things like BSMMU opening a new department rather than strengthening NIPSOM. (A development partner)

Still, a minority reflected on 'lack' of consistency in the outcomes:

So what happened in case of RF that a number of interesting pieces happened but somehow the orchestration was not done in a way that resonates as there was not much consistence in the kind of results from the different pieces. (An NGO partner)

Finally, the quality of the effort was also challenged by a few and the issue of concerted and coordinated efforts for generating a 'momentum' was also raised.

\section{Feedback from round-table dialogue with the stakeholders}

The concluding round-table dialogue brought the UHC grantees together so that they can share their experiences and learning related to their particular projects with other invited stakeholders. They discussed and debated the challenges and opportunities facing Bangladesh's journey towards UHC, in order to find a path forward on a consensus basis. A senior executive from the Asia office of the RF also attended the meeting, presenting an opportunity to interact and hear their side of the story.

Almost all the grantees and the participants in the meeting agreed that UHC is a matter of shared responsibilities of different stakeholders, both in the public and non-state sectors. However, the need for having adequate support and collaboration from other relevant ministries, such as the ministry of finance, ministry of planning, ministry of local government, ministry of food and agriculture, was also given due importance. All the RF grantees expressed interest in continuing the pace with appropriate coordination and collaboration mechanism in place.

\section{DISCUSSION}

This study explored how strategic contribution of the RF investments in Bangladesh (during 2010-2013) 'connected' different constituencies ('dots') in the government and non-state sectors, providing the initial thrust for 'generating a momentum for UHC' in the country (figure 1). Findings reveal important scenarios regarding how investments at different policy and practitioners levels, both individually and institutionally, helped in mobilising the stakeholders to come together, to discuss and debate the core concepts and components of UHC to reach a consensus, and identified relevant activities for implementation. The implication of these findings for possible entry points for initiating activities to advance UHC agenda in countries like Bangladesh is also discussed.

The 'multi-pronged, multi-sectoral' investment strategy of the RF THS initiative has been successful in rallying diverse stakeholders from health sector and beyond behind the UHC agenda in the critical inception phase in Bangladesh, a country characterised by 'low resources but high commitment' for UHC. ${ }^{5}$ For example, the RF THS grants simultaneously targeted and thereby, also connected, the academia, the non-profit development sectors (NGOs) and the news media for building awareness on UHC core concepts, emphasising the importance of quality and equity of services provided, and skill-building for UHC facilitation such as building capacity for analysing National Health Accounts, which helped in designing the HCFS for achieving UHC in the coming years. These activities sensitised relevant stakeholders towards the cause of UHC and mobilised them in the initial stage. Further, it helped different domains of stakeholders (relevant to UHC) with diverse interest and motivation, to build a working consensus for UHC (regarding its scope, components and priorities) and to push it high up in the policy agenda at a time when UHC was a relatively novel concept in the country, especially in the public sector. Additionally, experiences gathered in the process of implementing UHC projects (eg, barriers encountered and coping mechanisms) seasoned them to test innovations in a low resource-setting country like Bangladesh.

The insights from the implementation of the pilot projects, as revealed in the study findings, provided identification of probable opportunities and entry points for initiating UHC-related activities in the country. For example, differences were observed among stakeholders (coming from different backgrounds) with respect to understanding on various aspects of UHC including its 
scope and implementation, which is plausible. ${ }^{20} \mathrm{~A}$ UHC awareness and advocacy campaign for those high up in the policy and practice levels in the supply side may be an effective entry point to start with. Interestingly, the stakeholders conceptualised UHC as an improvement on previous work on 'health for all', and therefore, may be a comfortable entry point to reverse the 'missed opportunities' as some stakeholders thought. ${ }^{10}$ The stewardship role of the government, especially for coordinating intra-ministerial (health and family-welfare ministry, MoHFW) and inter-ministerial (other relevant ministries like finance, planning, women affairs) activities as well as mobilising necessary resources for UHC is also reiterated by the study participants which may be leveraged as strategic entry point for planning and financing UHC. This is encouraging as global experiences show that sustained political commitment from the highest level of government and public financing for health are the two essential requisites for implementing UHC agenda in any country. ${ }^{2}$

Interestingly, though the KIs were unanimous about the catalytic role played by the RF grants in initiating UHC discourse in the country, they were also critical regarding non-inclusivity of all stakeholders, lack of coordination and orchestration among the different investments (many stones were thrown and many windows have opened), leaving the country with work half-done (the curry has not been cooked yet...), and absence of plan to use the energy released by the momentum to scale up successful pilots. These limitations of the RF initiatives in Bangladesh should be taken into consideration for planning an inclusive, integrated and consensus approach to introduce UHC initiatives in countries with similar socioeconomic status. Further studies are warranted on how this can be done, aligned with the levels of conceptual understanding and interests of the key stakeholders in public and non-state sectors.

\section{Study limitations}

We reviewed reports of the 17 RF THS funded projects (completed and on-going at the time of study with available reports) directly relevant to facilitating UHC-related activities, excluding grants in areas such as fund for the Lancet Commission for Bangladesh series (Bangladesh: Innovation for UHC 2013) ${ }^{21}$ and fund for organising a satellite session on progress of UHC in Bangladesh at the PMAC in 2015. Review of these activities, including review of the completed reports of the on-going projects, might have provided additional perspectives to the results and added value to the conclusion. However, we covered the key projects directly related to the implementation of UHC in the RF THS portfolio, and thus mostly covered the ground for making sound conclusion about the 'catalytic' role of these grants for initiating UHC process in the country. Lastly, bias in responses by the KI respondents might have occurred due to their possible perception about the researchers being allied with the funder. An attempt to reduce this was done by explicitly distancing the researchers from the funding agency (RF) as employees of the BRAC JPG School of Public Health, and also, instructing the researchers to remain neutral in their interactions.

\section{CONCLUSION}

During the early years around 2010-2011, when the UHC was relatively a novel concept in the country and confusion remained about its scope and contents, the strategic investments of the RF THS initiative played a catalytic role in sensitising and mobilising different constituencies for concerted activities. This generated the thrust ('momentum') that was necessary to undertake necessary first steps. Included among these were awareness on scope and contents of UHC for consensus understanding, coalition-building for actions and evidence-based advocacy in a pluralistic health systems environment. Learnings from this strategy may be of help for countries under similar conditions of 'low resource, apparent commitment, but poor governance', on their journey towards UHC.

Contributors SMA conceptualised and designed the study protocol, critically interpreted data and drafted the manuscript. LBR and NN prepared data collection tools, analysed and interpreted data, and provided inputs to the draft. NN and TH organised the Klls and the dissemination and discussion meeting with stakeholders, and organised the data for framework analysis. SMA finalised the manuscript with feedback from the co-authors. All authors read the final manuscript and approved its submission.

Funding The study was funded by the Rockefeller Foundation (RF grant number THS\#329) to the Centre of Excellence for Health Systems and Universal Health Coverage, BRAC JPG School of Public Health, BRAC University, through icddr,b.

Competing interests The authors were employees of the Centre of Excellence for Health Systems and Universal Health Coverage, BRAC JPG School of Public Health, BRAC University, at the time of conducting this study. However, all the authors joined the Centre after 2013 and were not involved directly or indirectly in the conduction of the grants activities.

Patient consent for publication Not required.

Ethics approval This study was approved by the ethics review committee of the BRAC JPG School of Public Health, BRAC University (Ethics Reference No. 97 dated 5 August 2015).

Provenance and peer review Not commissioned; externally peer reviewed.

Data sharing statement The project reports are archived in the institutional repository of BRAC JPG School of Public Health. These may be made available from the corresponding author on reasonable request. The government docs are available in the websites of the respective departments and ministries.

Open access This is an open access article distributed in accordance with the Creative Commons Attribution Non Commercial (CC BY-NC 4.0) license, which permits others to distribute, remix, adapt, build upon this work non-commercially, and license their derivative works on different terms, provided the original work is properly cited, appropriate credit is given, any changes made indicated, and the use is non-commercial. See: http://creativecommons.org/licenses/by-nc/4.0/.

\section{REFERENCES}

1. Beattie A, Yates R, Noble DJ. Accelerating progress towards universal health coverage in Asia and Pacific: improving the future for women and children. BMJ Glob Health 2016;1(Suppl 2):i12-8.

2. Reich MR, Harris J, Ikegami N, et al. Moving towards universal health coverage: lessons from 11 country studies. Lancet 2016;387:811-6.

3. McKee M, Balabanova D, Basu S, et al. Universal health coverage: a quest for all countries but under threat in some. Value Health 2013;16:S39-S45. 
4. Kelsall T, Hart T, Laws E. Political settlements and pathways to universal health coverage. Overseas Development Institute (ODI) Working Paper No. 432: ODI 2016.

5. Hassan M. Political Settlement Dynamics in a Limited-Access Order: The Case of Bangladesh. BIGD Working Paper Series No. 20: BRAC Institute of Governance and Development 2014.

6. Khan SU, Saqib OF. Political Instability and Inflation in Pakistan MPRA paper No 2009;13056 http://mpra.ub.uni-muenchen.de/ 13056/.

7. Ahmed SM, Evans TG, Standing $\mathrm{H}$, et al. Harnessing pluralism for better health in Bangladesh. Lancet 2013;382:1746-55.

8. World Health Organization \& Bangladesh. Ministry of Health and Family Welfare. Success factors for women's and children's health: Bangladesh: World Health Organization. 2015 http://www.who.int/ iris/handle/10665/178623 (accessed 9 May 2018).

9. Balabanova D, Mills A, Conteh L, et al. Good Health at Low Cost 25 years on: lessons for the future of health systems strengthening. Lancet 2013;381:2118-33.

10. Dkhimi F. Will UHC be a missed opportunity for comprehensive health care? Institute of Tropical medicine 2014 http://www.inte rnationalhealthpolicies.org/will-uhc-be-a-missed-opportunity-forcomprehensive-health-care/ (accessed 9 May 2018).

11. Ahmed SM, Rawal LB, Chowdhury SA, et al. Cross-country analysis of strategies for achieving progress towards global goals for women's and children's health. Bull World Health Organ 2016;94:351-61.

12. World Health Assembly. Sixty Fourth World Health Assembly Agenda 13.4: Sustainable health financing structures and universal coverage: WHA. 2011 http://apps.who.int/medicinedocs/documents/s21474en/ s21474en.pdf (accessed 9 May 2018).
13. The Rockefeller Foundation (RF) Evaluation Office. Lessons from The Rockefeller Foundation's Transforming Health Systems (THS) Initiative: Country Case Study Brief: Bangladesh. The RF 2015 https://assets.rockefellerfoundation.org/app/uploads/ 20151118135115/Transforming-Health-Systems-Country-CaseStudy-Briefs.pdf (accessed 18 Feb 2019).

14. Gale NK, Heath G, Cameron E, et al. Using the framework method for the analysis of qualitative data in multi-disciplinary health research. BMC Med Res Methodol 2013;13:117.

15. Ritchie J, Lewis J. Qualitative research practice: a guide for social science students and researchers. London: Sage, 2003.

16. Murtagh J, Dixey R, Rudolf M. A qualitative investigation into the levers and barriers to weight loss in children: opinions of obese children. Arch Dis Child 2006;91:920-3.

17. Ayatollahi H, Bath PA, Goodacre S. Factors influencing the use of IT in the emergency department: a qualitative study. Health Informatics J 2010;16:189-200.

18. Leapfrogging. Available from: https://leapfrog.cl/en/leapfrogging (accessed 16 Jun 2019).

19. Directorate general of Health Services, Ministry of Health and Family Welfare, Government of BangladeshHealth Bulletin;2018 http://www.dghs.gov.bd/images/docs/Publicaations/HB\%202018\% 20final.pdf.

20. Abiiro GA, De Allegri M. Universal health coverage from multiple perspectives: a synthesis of conceptual literature and global debates. BMC Int Health Hum Rights 2015;15:17.

21. Bangladesh: Innovation for UHC. https://www.thelancet.com/series/ bangladesh (accsessed 16 Jun 2019). 